\title{
Organizational Strategy and Staffing
}

\author{
John P. Hausknecht \\ Cornell University \\ and \\ Patrick M. Wright \\ Cornell University
}

\begin{abstract}
In this chapter, we draw linkages between theory and research from strategic human resource management (and its focus on predicting unit/firm performance) with the key issues and empirical findings from the staffing and selection literature (and its focus on predicting individual performance). We organize the chapter around the fit and flexibility framework (Wright \& Snell, 1998) to discuss the dual concerns of fitting staffing and selection systems to strategic needs while simultaneously enabling flexibility to respond to future demands. Implications for research and practice explain how such an approach may alter and enhance conventional views regarding staffing system characteristics such as the types of criteria, knowledge, skills, abilities, and other characteristics (KSAOs), and selection methods that are considered.
\end{abstract}

Key Words: staffing, selection, strategy, strategic human resource management, human capital

Although it has long been argued that staffing and selection practices should be compatible with organizational strategy and objectives (e.g., Dyer, 1983; Tichy, Fombrun, \& Devanna, 1982), the fields of strategy, strategic human resource management, and staffing/selection have developed largely in parallel. An unfortunate consequence of this trend is that the key insights from these fields are not widely known by staffing researchers and practitioners. Thus, the goal of this chapter is to bring together selected theory, principles, and findings from staffing and strategy research under a single framework. We use the fit and flexibility perspective from the strategic human resource management literature (Wright \& Snell, 1998) to examine how and why staffing and selection practices might differ depending on the organization's strategic goals. We then discuss implications of the framework for research and practice, particularly concerning the types of predictors and criteria that are considered under different approaches.

\section{Definitional Issues}

Broadly defined, strategy is "a central, integrated, externally oriented concept of how the business will achieve its objectives" (Hambrick \& Fredrickson, 2001, p. 49). Strategy essentially involves a firms competitive choices regarding where to compete, how to compete, and with what to compete (Noe, FFollenbeck, Gerhart, \& Wright, 2008); one component of the "with what" portion of this definition concerns decisions about staffing. Staffing, defined as the process of "acquiring, deploying, and retaining a workforce of sufficient quantity and quality to create positive impacts on the 
organizations effectiveness" (FFeneman \& Judge, 2009, p. 7), occupies a critical role in both setting strategic direction (i.e., understanding the capacity of existing human resources) and in implementing a chosen strategy (i.e., acquiring or upgrading necessary capabilities). Taken together, strategic staffing -has been defined as "the process of staffing an organization in future-oriented, goal-directed ways that support the business strategy of the organization and enhance its effectiveness" (Phillips \& Gully, 2009, p. 4). An important theme that underlies these definitions is that each describes activities and goals that traverse individual selection decisions, implying an emphasis on aggregate levels of human capital and connections to broader organizational concerns.

\section{Chapter Overview}

Our aim in this chapter is to provide a perspective that connects theory and research from strategic human resource management (and its focus on predicting unit/firm performance) with the key issues and empirical findings within the time-honored selection literature (and its focus on predicting individual performance). We begin by describing a theoretical perspective from the strategic human resource (HR) management literature - the fit and flexibility framework (Wright \& Snell, 1998) - to explain the dual concerns of fitting HR systems to strategic needs while simultaneously enabling flexibility to respond to future demands. Next, given that the fit and flexibility framework was developed in the broader context of human resource management (HRM), we discuss its specific applications to staffing and selection. We then address implications for research and practice, discussing how such an approach may alter and enhance conventional views. In particular, we examine how strategic considerations might influence the types of criteria, knowledge, skills, abilities, and other characteristics (KSAOs), and selection methods that are considered, while also shaping staffing system decisions and human capital management at broader levels. Note that although staffing encompasses a broad range of talent-related practices (e.g., fanning, recruitment, selection, succession, retention), given the focus of this handbook, we generally emphasize issues related to assessment and selection.

\section{Fit and Flexibility Framework}

The fit and flexibility model (Wright \& Snell, 1998) begins by establishing the basic elements of strategy formulationdefining mission and goals, examining internal strengths and weaknesses, and identifying external opportunities and threats - leading to the choice of a given strategy. Once a strategic direction has been established, the model suggests two possible paths. In the first, the HR function's primary role is strategy implementation, which involves translating the strategic direction into statements of required skills and behaviors, inferring the types of HR practices needed, and actually designing, developing, and delivering those practices. Thus, HR practices are designed to identify skills and behaviors that "fit" with the firm's established strategic direction; the greater the match or congruence, the more likely it is that the firm will realize higher performance.

Despite the sound logic of the fit perspective, Wright and Snell (1998) discuss several underlying assumptions that call into question its universal relevance. These include the presumption that the right set of employee skills and behaviors can be deduced based on the firm's strategy, that all HR practices can be specified and tightly controlled throughout the organization, and that the environment is stable enough that the established strategic goals remain relevant and 
appropriate while HR practices and policies are planned and executed. However, in dynamic and unpredictable environments, the HR function may be less able to anticipate HR needs and may have difficulty adapting to changing strategic direction, particularly given the time involved in redefining HR policies and practices and implementing those changes throughout the organization, Thus, the second key path of the model focuses on flexibility, suggesting that organizations embedded in dynamic and unpredictable environments might benefit from being capable of quickly reconfiguring HR activities and resources in response to changing demands (Wright \& Snell, 1998).

The flexibility concept suggests that HR should focus on more than fitting practices to strategy, recognizing instead that a broader range of employee skills and behaviors may be needed to remain competitive beyond the current strategy. In particular, flexibility is conceptualized along three main dimensions: (1) developing readily adaptable HR systems, (2) cultivating broadly skilled pools of human capital, and (3) promoting behavioral flexibility among employees. Within each dimension, distinctions are drawn between "resource flexibility" and "coordination flexibility" (Sanchez, 1995). Resource flexibility concerns the extent to which an organizational resource has numerous alternative uses and can be altered easily and quickly for those purposes. Coordination flexibility refers to the firms ability to resynthesize strategy and reconfigure and redeploy its resources. By considering resource and coordination flexibility in the context of HR practices, employee skills, and employee behaviors, the model suggests a novel alternative to the traditional concept of fitting HR to firm strategy.

\section{Fit, Flexibility, and Staffing}

Although the model was developed in the broader context of HRM, including (but not limited to) staffing and selection, the fit and flexibility framework provides a foundation for exploring how, when, and why particular staffing and selection practices are more or less appropriate in the broader context of organizational strategy. The framework reveals the value of attending to fit and flexibility at multiple levels-individual, group, and organization-and suggests a number of practical implications and directions for future research. We explore these issues in the following sections.

\section{Staffing and Fit}

The notion of "fit" has multiple connotations in the staffing and selection domain. Fit can be conceived in specific terms (i.e., person-job match), which is common in the assessment and selection literature, or more broadly (i.e., staffing systemstrategy alignment), as is typical in the areas of strategy and strategic HRM. Although theories and research strategies are somewhat distinct across these domains, there is value in incorporating ideas from the multiple perspectives to illuminate the potential benefits of taking a more inclusive view of staffing and selection. Drawing from the extant literature, three types of fit are discussed: (1) person- job match, (2) person-organization match, and (3) strategy-staffing match.

Fit as person-job match. A useful starting point for considering staffing and fit is the level of individual person-job match. The field of personnel selection was borne out of the need to systematically match individuals with jobs-as organizations grew larger and became more complex, formal procedures were needed to ensure that candidates had the KSAOs necessary for effective job performance (Snow \& Snell, 1993). Such an approach embodies much of the field of personnel selection today, as detailed job specifications and narrowly defined KSAOs guide choices regarding appropriate 
selection devices (e.g., cognitive ability tests, work samples, and structured interviews). Across decades of research, substantial empirical evidence shows that the person-job match approach is an effective means of identifying high performers (e.g., Schmidt \& Hunter, 1998). Applying the findings from person- job match research ensures that limited resources are not wasted on candidates who cannot perform the job and provides the basis for selection system legal defensibility.

Nevertheless, researchers have argued that approaching staffing solely as person-job match is limited in important ways. Snow and Snell (1993) portrayed the person-job match approach as overly static-focusing more on the job as it exists today and on individuals' present capabilities rather than their capacity to change (see also Cascio \& Aguinas, 2008). They also argued that important aspects of performance that reside at the interface between jobs (e.g., interdependence) are largely overlooked by a person-job match perspective. Other researchers have questioned the person-job match presumption that hiring individuals with higher levels of ability will necessarily translate into better organizational performance (Ployhart, 2004, 2006; Ployhart \& Schneider, 2002). Hence, despite obvious value and widespread acceptance, the linkages between the person-job match perspective and strategy for- mulation/implementation are limited to jobs that are narrowly defined, static, and relatively independent. Although strategy likely occupies at least some role in selection systems that are rooted in person- job match (e.g., organizational needs analysis), the focus remains on individual-level rather than organizational-level concerns.

Fit as person-organization match. In contrast to the view of staffing as person-job match, researchers have discussed the importance of selecting individuals for their fit with broader entities such as the organization or workgroup (e.g., Bowen, Ledford, \& Nathan, 1991; Judge \& Ferris, 1992; Kristof, 1996; Rynes \& Gerhart, 1990). For example, Bowen et al. (1991) stressed the importance of achieving fit between individual personality and the climate or culture of the organization. Judge and Ferris (1992) discussed how different strategic directions call for different characteristics of individuals. Schneider and Konz (1989) argued for analyzing jobs according to both present and future needs. Subsequent empirical research has indicated that recruiters indeed assess person-organization fit during the selection process; these perceptions are distinct from person-job fit perceptions and have been shown to influence hiring recommendations and job offer decisions (Cable \& Judge, 1997; Kristof-Brown, 2000).

Incorporating judgments of person-organization fit into the selection process is consistent with fitting HR practices to the strategic needs of the firm (Wright \& Snell, 1998). Under this approach, job descriptions reflect the outcomes of job analysis, but also incorporate information regarding the strategic needs of the firm or the competencies that underlie successful team performance (Schneider \& Konz, 1989; Snow \& Snell, 1993). Executives and top-level managers are screened not just for KSAOs, but also for their match with the organizations competitive strategy (Olian \& Rynes, 1984; Tichy et ah, 1982). Although the logic of person- organization match gives more attention to strategic concerns, Snell and Snow (1993) criticized its reactive focus (i.e., viewing staffing as an outcome rather than driver of strategy) and potential to create organizational inertia (i.e., selecting leaders who are too tightly linked with strategies that quickly become outdated). Furthermore, such a perspective generally remains tied to the individual level despite contentions that staffing may have a greater impact when considered as a higher-order phenomenon (Ployhart, 2004; Ployhart \& Weekley, 2010). 
Fit as strategy-staffing match. A third perspective on fit moves away from the individual level to consider fit as the match between (1) strategy and firm/unit-level staffing policies, philosophies, or practices, or (2) strategy and collective human capital. Regarding the former, Olian and Rynes (1984) suggested that certain selection criteria and selection techniques would be more or less appropriate depending on the type of organizational strategy. Schuler and Jackson (1987) described how different approaches to competitive strategy (innovation, quality, cost) guide what employee role behaviors are sought (e.g., low versus high risk taking) and what human resource practices are adopted (e.g., staffing internally versus externally). In an empirical study, Youndt, Snell, Dean, and Lepak (1996) found that human-capitalenhancing HR practices (including selective staffing) were more strongly related to firm performance for those firms pursuing a high-quality rather than low-quality manufacturing strategy.

Several researchers have approached the strategy- staffing match using measures of collective human capital (i.e., aggregate characteristics of actual people rather than characteristics of the practices used to select them). For example, Wright, Smart, and McMahan (1993) studied college basketball teams and found that the relationship between actual team skill levels and performance depended on the coach's strategy. Ployhart, Weekley, and Ramsey (2009) studied an organization pursuing a service strategy and found that both the stock and flow of actual human capital (operationalized in terms of unit-level service employee competencies) predicted unit effectiveness. Note that these studies depart from individual-level perspectives in viewing the strategic value of human capital as residing in aggregate rather than individual KSAOs.

More recently, Ployhart and Moliterno (2011) provided a multilevel theoretical model of human capital that helps to bridge individual (micro) and organizational (macro) perspectives on staffing. Critical to their model is the notion that organizations might create or "assemble" human capital as a unit-level resource. That is, although individual KSAOs provide the foundation for human capital as a valuable resource, the authors argue that units will differ in how well they can leverage these resources because of variability in "emergence enabling states" (i.e., behavioral, cognitive, and affective states that facilitate emergence of unit-level human capital). Factors such as coordination, communication, memory, learning, cohesion, and trust enable the unit to maximize KSAOs that reside collectively within the unit, and when they are present, human capital is said to emerge as a valuable unit-level resource.

Summary of staffing and fit. Consistent with Wright and Snell (1998), organizations embedded in stable, predictable environments should benefit from matching staffing practices to organizational strategy, Decision makers can work from the outcomes of the strategy formulation process to identify the skills and behaviors required for strategy implementation, working toward accurate forecasts of the quality (required skills, behaviors) and quantity (number of positions) of human capital required. A main responsibility of the staffing function is to develop a sound understanding of the organizations strategy and objectives today, forecast talent needs and composition, and choose practices and policies that support these goals, However, it is also evident that the assumptions of the fit perspective (environmental stability, identifiable skills, accurate forecasts) will not always hold, particularly in light of economic shifts, technological changes, globalization, and other workforce trends that point to far less static and predictable conditions (Cascio \& Aguinas, 2008; Howard, 1995). Thus, as discussed in the next section, organizations may benefit not only from linking staffing to strategy, but from 
creating flexible staffing strategies and practices that can accommodate shifts in strategic direction and provide greater responsiveness to changing environmental demands.

\section{Staffing and Flexibility}

In contrast to the fit perspective, a focus on flexibility assumes that staffing takes place in complex and unpredictable environments, that decision makers may not be able to ascertain which skills and behaviors will be required for future strategy implementation, and that the availability of the required capabilities is, at best, difficult to forecast (Wright \& Snell, 1998). In these instances, resources may be better directed to developing organizational responsiveness by acquiring human capital with broad and heterogeneous skills and behaviors. Forecasting is deemphasized in favor of policies and practices that enable the organization to quickly reconfigure human resources to meet changing demands. Focusing on flexibility implies the development of a "participative infrastructure," meaning that employees take on a more important role in developing, identifying, and exploiting new strategies (Wright \& Snell, 1998). Thus, HR activities (such as staffing) become an important foundation for competitive strategy rather than the means by which it is enacted (Snow \& Snell, 1993). We consider flexibility as it relates to staffing at both individual/team and system/practice levels.

Flexibility in individuals and teams. One approach to promoting flexibility is to select individuals who are themselves flexible or adaptable (Boudreau \& Ramstad, 1997; Cascio \& Aguinas, 2008; Snow \& Snell, 1993; Wright \& Snell, 1998). To this end, Pulakos, Arad, Donovan, and Plamondon (2000) developed a taxonomy of adaptive performance (distinct from job performance) based on analysis of thousands of critical incidents from a wide variety of jobs. Results supported an eight-factor taxonomy of adaptive performance: (1) dealing with uncertain and unpredictable work situations, (2) learning new work tasks, technologies, and procedures, (3) handling emergencies or crisis situations, (4) handling work stress, (5) solving problems creatively, (6) demonstrating interpersonal adaptability, (7) demonstrating cultural adaptability, and (8) demonstrating physically oriented adaptability. As the authors described, an important implication for selection is that the individual attributes that are important for adaptive performance (and the predictors used to assess them) may differ from the attributes that are most closely associated with effective task performance. Indeed, further research by Pulakos and colleagues has shown that adaptability-focused measures provide incremental validity beyond cognitive ability and personality in predicting supervisor ratings of adaptive performance (Pulakos et al., 2002).

Adaptability has also been conceptualized and measured at the team level. For example, LePine (2003) defined role structure adaptation in terms of a team's reactive and nonscripted adjustment to changing demands and found that four aggregated individual attributes-cognitive ability, achievement, dependability, and openness to experience- explained variance in role structure adaptation and team performance. Similar to individual-level adaptability research (Pulakos et ah, 2002), an important conclusion of the study was that the individual differences contributing to performance in changing situations are not the same as those that predict performance in routine situations.

Both the individual and team-level perspectives on adaptability relate to Wright and Snell's (1998) discussion of flexibility in employee skills and behaviors. For example, selecting adaptable individuals contributes to resource flexibility in employee skills by increasing the stock of employees who can perform new tasks and adapt to changing task demands 
over time. Broadening the focus to the team level creates resource flexibility in employee behaviors by ensuring that team members have the right mix of attributes necessary to respond to unforeseen changes in the work environment. Coordination flexibility is also enhanced, as adaptable individuals can be redeployed more easily (and more successfully) to other parts of the organization.

System/practice-level flexibility. A second lens on flexibility emphasizes the organization's capacity to adapt staffing systems, policies, and practices to changing organizational needs. Wright and Snell (1998) considered HR practice flexibility in terms of differences in practices across locations or business units, the extent to which practices can be applied to different jobs, and the speed with which practices can be modified. At the less flexible end of the continuum, they described highly centralized HR practices that, when rigidly applied throughout the organization, may lead to practices that do not fit well with the competitive demands of particular jobs or individual locations. In addition, they argued that as organizations grow larger and become more bureaucratic, they become more resistant to changing institutionalized practices. Consequently, HR practices can become too firmly entrenched, limiting the organization's ability to match employee skills and behaviors with competitive needs. Furthermore, it may take years before the effects of HR practices can be fully observed, which often runs counter to the need for more timely evaluation.

The limiting effects of inflexibility have received empirical support in several recent studies. Bhattacharya, Gibson, and Doty (2005) found that HR practice flexibility was positively associated with firm performance after controlling for the presence of high-performance HR practices (e.g., selective staffing), suggesting that building flexibility into HR practices adds uniquely to the prediction of firm performance. Ketkar and Sett (2009) reported similar effects linking HR practice flexibility with measures of financial, operating, and employee performance.

The actual practices used to achieve staffing flexibility have also been addressed. Studies indicate growing use of temporary, part-time, and contract- based employment modes as a means of controlling costs and accommodating fluctuations in product or service demand (Gramm \& Schnell, 2001; Houseman, 2001; Smith, 1997). Lepak and Snell (1999) suggested that strategic considerations often lead to different employment modes for different employee groups within the same firm and developed a theoretical model that articulated how the value and uniqueness of human capital should drive choices regarding employment modes, employment relationships, and HR configurations. Consistent with the flexibility concepts described by Wright and Snell (1998), a key component of the model is its attention to shifting HR configurations to accommodate changing needs. To this end, Lepak, Takeuchi, and Snell (2003) found that greater use of knowledge-based employment and contract work was positively associated with firm performance, suggesting that these employment modes provide greater coordination and resource flexibility, and ultimately enable firms to acquire and reconfigure human capital more quickly in response to environmental demands.

Summary of staffing and flexibility. Organizations faced with unpredictable and uncertain competitive environments may benefit from a more flexible approach to staffing. One approach involves staffing the organization with individuals who have the capacity to adapt to changing work situations. A second consideration relates to the organizations ability to adapt staffing policies and practices to meet changing demands. Different employment modes may also help organizations 
meet the need for flexibility in staffing.

\section{Implications and Future Research}

In our discussion of staffing and selection from fit and flexibility perspectives, we considered three approaches to fit (person-job match, person-organization match, and strategy-staffing match) and two perspectives on flexibility (flexibility in individuals/ teams and system/practice-level flexibility). Below we discuss how these views might alter staffing and selection research and practice.

\section{Practical Implications}

Approaching staffing from the perspective of person-job match has a long and rich history. Indeed, many of the chapters in this book provide excellent guidance with regard to job analysis methods, KSAO assessment, and validation strategies. Thus, we do not repeat this advice here, focusing instead on how staffing and selection might differ when considering these activities more broadly than as person-job match. We organize these suggestions into two main categories: (1) those that influence the types of criteria, KSAOs, and selection methods that are considered, and (2) those that shape staffing and human capital management at broader levels.

Criteria, KSAOs, and selection method considerations. Promoting "fit" beyond person-jot match can occur in at least three ways. First, strategic goals can be explicitly incorporated into the job analysis process (Schneider \& Konz, 1989), Ignoring broader concerns such as person-organization fit runs the risk that selection systems will identify highly qualified individuals who do not fit the organization's culture or strategic mission (Bowen et al., 1991; Ployhart \& Weekley, 2010), which can lead to higher turnover and excessive recruitment and selection costs. Second, given findings that better person-organization fit is associated with higher contextual performance, lower turnover, and more positive work attitudes (Kristof- Brown, Zimmerman, \& Johnson, 2005), recruiters can be trained to evaluate person-organization fit during the hiring process (in addition to person- job match). Cable and Judge (1997) suggested that structured interviews might be modified to allow for such assessments. Third, validation strategies might expand the criterion space beyond job performance to include factors such as contextual performance and work withdrawal (absenteeism, turnover), Individual job performance measures should not necessarily be expected to reveal the validity of person-organization fit assessments, and indeed, meta- analytic evidence shows that they are only weakly related to overall job performance (Kristof-Brown et al., 2005).

Organizations might build greater "flexibility" through several means. One approach involves incorporating assessments of adaptability into the selection process (LePine, Colquitt, \& Erez, 2000). Although flexibility may not be critical for the current job (narrowly defined and as it exists today), identifying individuals with a willingness to adapt to changing demands may have long-term value. Such a focus necessitates a broader criterion view to include relevant dimensions of adaptive performance. Given that different work settings require different types of adaptability (Pulakos et ah, 2000), it is incumbent upon managers and human resource personnel to determine which adaptive performance characteristics are appropriate to assess. Research suggests that certain types of predictors (e.g., general cognitive ability) forecast task performance in both stable and dynamic contexts, whereas others (e.g., certain personality dimensions, adaptability- 
focused predictors) are more effective at explaining adaptive rather than task performance (LePine et ah, 2000; Pulakos et ah, 2002). A second means of addressing flexibility is at the team or group level. The prevalence of team-based work design calls for staffing teams with an effective mix of both technical and interpersonal skills, yet the former are often emphasized over the latter. Recent examples show that staffing for the team calls for a wider set of KSAOs beyond technical competence (e.g., social skills, personality, conflict resolution) and also expands the criterion domain to include contextual performance and adaptability (LePine, 2003; Stevens \& Campion, 1999). Several studies show that teamfocused assessments predict both role and contextual performance and provide incremental validity beyond general cognitive ability (Morgeson, Reider, \& Campion, 2005; Mumford, Van Iddekinge, Morgeson, \& Campion, 2008).

Broader considerations. Fit and flexibility considerations are also germane to how the organization structures its staffing practices (in broad terms) and how it manages existing stocks of human capital. As discussed above, fit considerations involve matching staffing practices to strategic goals, and in some instances, significant investments in human capital may actually add little value to the firm if these activities are misaligned (Youndt et al., 1996). This suggests that staffing specialists must understand the strategic needs of the firm or business unit before delving into the details of selection system design (Tichy et al., 1982). Furthermore, although selection systems are needed to provide a continuous stream of qualified employees that can meet day-to-day operational demands (leading to a focus on individual-level validation studies) staffing specialists might also focus on human capital "stocks and flows," which have been conceived as having greater potential as a source of sustained competitive advantage (Ployhart et al., 2009; Ployhart, Van Iddekinge, \& MacKenzie, 2011).

Staffing system flexibility can be enhanced in several ways, including creating systems that are responsive to local needs (particularly in large organizations) and designing selection systems that can be easily modified as strategic priorities evolve. Moreover, developing a reliable pool of alternative employment modes such as temporary, part-time, and contract-based employment promotes staffing flexibility vis-a-vis a sole reliance on permanent, full-time hires. Tracking existing human capital - via skills databases, succession management systems, and so on-allows organizations to rapidly redeploy existing employees where their skills are needed most.

\section{Research Implications}

Relative to the expansive literature on person- job match, much less is known about selecting individuals based on adaptability, person-organization fit, or their ability to function in team environments. Although several studies have addressed these topics, the cumulative knowledge is rather limited, particularly as compared to what is known about person-job match. In addition, only recently has research begun to examine the flow of human capital (and their associated skill bases) through the organization, and seldom has such analysis explored how the flow changes in response to environmental changes.

Furthermore, empirical research addressing staffing system/practices, collective human capital, and firm performance is also in its infancy, suggesting another obvious area for further research. To this end, and as evident from our discussion, the predictors, criteria, and levels of analysis must necessarily change to address staffing from fit and flexibility 
perspectives. In addition, little research has examined the variability in staffing practices used across businesses, countries, or even regions within large multinational companies, much less the effectiveness of allowing or not allowing for such variability.

\section{Conclusions}

Despite recognition that staffing and selection practices can play a significant role in driving or implementing organizational strategy, the fields of strategy, strategic human resource management, and staffing/selection have not been closely linked. This chapter outlines a means by which key insights from these fields can be integrated, implemented, and further refined through additional empirical investigation. The key to these endeavors will be conceptual models that draw linkages between staffing/selection and organizational strategy, and the present framework offers a potential source of guidance in this regard.

\section{References}

Bhattacharya, M., Gibson, D. E., \& Doty, D. H. (2005). The effects of flexibility in employee skills, employee behaviors, and human resource practices on firm performance. Journal of Management, 31, 622-640.

Boudreau, J. W, \& Ramstad, P. M. (1997). Measuring intellectual capital: Learning from financial history. Human Resource Management, 36, 343-356.

Bowen, D. E., Ledford, G. E., Jr., \& Nathan, B. R. (1991). fiiring for the organization, not the job. Academy of Management Executive, 5, 35-51.

Cable, D. M., \& Judge, T. A. (1997). Interviewers perceptions of person-organization fit and organizational selection decisions. Journal of Applied Psychology, 82, 546-561.

Cascio, W. E, \& Aguinas, H. (2008). Staffing twenty-first- century organizations. The Academy of Management Annals, 2, 133-165.

Dyer, L. (1983). Bringing human resources into the strategy formulation process. Human Resource Management, 22, 257271.

Gramm, C. L., \& Schnell, J. E (2001). The use of flexible staffing arrangements in core production jobs. Industrial and Labor Relations Review, 54, 245-258.

Hambrick, D. C., \& Fredrickson, J. W. (2001). Are you sure you have a strategy? Academy of Management Executive, 15, 48-59.

Heneman, H. G., III., \& Judge, T. A. (2009). Staffng organizations. Middleton, WI: McGraw-Hill/Irwin.

Houseman, S. N. (2001). Why employers use flexible staffing arrangements: Evidence from an establishment survey. Industrial and Labor Relations Review, 55, 149-170.

Howard, A. (1995). A framework for work change. In A. Howard (Ed.), Ihe changing nature of work (pp. 3-44). San Francisco, CA: Jossey-Bass.

Judge, T. A., \& Ferris, G. R. (1992). The elusive criterion of fit in human resources staffing decisions. Human Resource Planning, 15, $451-617$.

Ketkar, S., \& Sett, P. K. (2009). HR flexibility and firm performance: Analysis of a multilevel causal model. International Journal of Human Resource Management, 20, 1009-1038.

Kristof, A. L. (1996). Person-organization fit: An integrative review of its conceptualizations, measurement, and implications. Personnel Psychology, 49, 1-49.

Kristof-Brown, A. L. (2000). Perceived applicant fit Distinguishing between recruiters' perceptions of person- job and 
person-organization fit. Personnel Psychology, 53, 643-671.

Kristof-Brown, A. L., Zimmerman, R. D., \& Johnson, E. C. (2005). Consequences of individuals' fit at work: A meta-analysis of person-job, person-organization, person- group, and person-supervisor fit. Personnel Psychology, 54 281-342.

Lepak, D. E, \& Snell, S. A. (1999). The human resource architecture: Toward a theory of human capital allocation and development .Academy of Management Review, 24, 31-48.

Lepak, D. E, Takeuchi, R., \& Snell, S. A. (2003). Employment flexibility and firm performance: Examining the effects of employment mode, environmental dynamism, and technological intensity. Journal of Management, 22, 681-703.

LePine, J. A. (2003). Team adaptation and postchange performance: Effects of team composition in terms of members cognitive ability and personality. Journal of Applied Psycholog) 88, 27-39.

LePine, J. A., Colquitt, J. A., \& Erez, A. (2000). Adaptability to changing task contexts: Effects of general cognitive ability, conscientiousness, and openness to experience. Persomi Psychology, 53, 563-593.

Morgeson, F. E, Reider, M. H., \& Campion, M. A. (2005), Selecting individuals in team settings: The importance of social skills, personality characteristics, and teamwork knowledge. Personnel Psychology, 58, 583-611.

Mumford, T. V., Van Iddekinge, C. H., Morgeson, F. P., It Campion, M. A. (2008). The Team Role Test: Development and validation of a team role situational judgment test, Journal of Applied Psychology, 93, 250-267.

Noe, R. A., Hollenbeck, J. R, Gerhart, B, \& Wright, P. M, (2008). Human research management: Gaining a competitin advantage. New York: McGraw-Hill/Irwin.

Olian, J. D., \& Rynes, S. L. (1984). Organizational staffing Integrating practice with strategy. Industrial Relations, 2 | 170183.

Phillips, J. M., \& Gully, S. M. (2009). Strategic staffing. Upper Saddle River, NJ: Pearson.

Ployhart, R. E. (2004). Organizational staffing: A multilevel review, synthesis, and model. Research in Personnel anl Human Resources Management, 23, 121-176.

Ployhart, R. E. (2006). Staffing in the 21st century: New challenges and strategic opportunities. Journal of Management, $32,868-897$.

Ployhart, R. E., \& Moliterno, T. P. (2011). Emergence of the human capital resource: A multilevel model. Academy if Management Review, 36, 127-150.

Ployhart, R. E., \& Schneider, B. (2002). A multi-level perspective on personnel selection research and practice: Implications for selection system design, assessment, and construct validation. In F. J. Yammarino \& F. Dansereau (Eds.), Research in multi-level issues: Vol. 1. The many faces of multi-level issue (pp. 95-140). Oxford: Elsevier.

Ployhart, R. E., \& Weekley, J. A. (2010). Strategy, selection, and sustained competitive advantage. In J. L. Farr \&N,I Tippins (Eds.), Handbook of employee selection (pp. 195-212). New York: Taylor and Francis Group.

Ployhart, R. E., Van Iddekinge, C. H., \& MacKenzie, W.I.,jt (2011). Acquiring and developing human capital in service contexts: The interconnectedness of human capital resources. Academy of Management Journal, 54, 353-368.

Ployhart, R. E., Weekley, J. A., \& Ramsey, J. (2009). The consequences of human resource stocks and flows: A longitudinal examination of unit service orientation and unit effectiveness. Academy of Management Journal, 52, 996-1015.

Pulakos, E. D., Arad, S., Donovan, M. A., \& Plamondon, K. E. (2000). Adaptability in the workplace: Development of a taxonomy of adaptive performance. Journal of Applied Psychology, 85, 612-624.

Pulakos, E. D., Schmitt, N., Dorsey, D. W, Arad, S., Hedge, J. W., \& Borman, W. C. (2002). Predicting adaptive performance: Further tests of a model of adaptability. Human Performance, 15, 299-323.

Rynes, S., \& Gerhart, B. (1990). Interviewer assessments of applicant fit: An exploratory investigation. Personnel Psychology, 43, 13-35.

Sanchez, R. (1995). Strategic flexibility in product competition. Strategic Management Journal, 16, 135-159.

Schmidt, F. L., \& Hunter, J. E. (1998). The validity and utility of selection methods in personnel psychology: Practical and 
theoretical implications of 85 years of research findings. Psychological Bulletin, 124, 262-274.

Schneider, B., \& Konz, A. M. (1989). Strategic job analysis. Human Resource Management, 28, 51-63.

Schuler, R. S., \& Jackson, S. E. (1987). Linking competitive strategies with human resource management practices. Academy of Management Executive, 1, 207-219.

Smith, V. (1997). New forms of work organization. Annual Review of Sociology, 23, 315-339.

Snow, C. C., \& Snell, S. A. (1993). Staffing as strategy. In N. Schmitt \& W. Borman (Eds.), Personnel selection in organizations (pp. 448-479). San Francisco: Jossey-Bass.

Stevens, M. J., \& Campion, M. A. (1999). Staffing work teams: Development and validation of a selection test for teamwork settings. Journal of Management, 25, 207-228.

Tichy, N. M., Fombrun, C. J., \& Devanna, M. A. (1982). Strategic human resource management. Sloan Management Review, 23, 47-61.

Wright, P. M, Smart, D. L, \& McMahan, G. C. (1995). Matches between human resources and strategy among NCAA basketball teams. Academy of Management Journal, 38 1052-1074.

Wright, P. M., \& Snell, S. A. (1998). Toward a unifying framework for exploring fit and flexibility in strategic human resource management. Academy of Management Review, 23, 736-772.

Youndt, M. A., Snell, S. A., Dean, J. W, Jr., \& Lepak, D. P. (1996). Human resource management, manufacturing strategy, and firm performance. Academy of Management Journal, 39, 836-866. 